(CYP) IAPT, so I fail to see the relevance. In fact, this stark statistic is probably one of the reasons why CYP-IAPT places such a huge emphasis on participation - an element of CYP-IAPT that is completely disregarded in this article.

Admittedly, the implementation of outcome data collection has been problematic, but this is a huge development on a massive scale. This is not about monitoring data in one service, this is about setting up a national system for monitoring and comparing outcomes. Anyone can set up a spreadsheet for a few patients, but linking multiple electronic patient record systems into a central reporting mechanism is a bit more of an undertaking.

Catherine J. Swaile, Mental Health Commissioner, Haringey, UK, email: cathyswaile@hotmail.com

Note: The opinions expressed here are the author's own and not necessarily those of any clinical commissioning group, or Haringey Council.

1 Timimi S. Children and Young People's Improving Access to Psychological Therapies: inspiring innovation or more of the same? BJPsych Bull 2015; 39: 57-60

doi: $10.1192 /$ pb.39.5.261a

\section{Raising the standard: it's time to review the MRCPsych examinations}

The MRCPsych examinations are the qualifying examinations for membership with the Royal College of Psychiatrists and are generally undertaken in the second and third year of core training. In combination with workplace-based assessments and the Annual Review of Competence Progression (ARCP) the exams are essential to progressing to advanced training and eventually a Certificate of Completion of Training (CCT). The exams currently involve three multiple choice (MCQ) format papers and a single clinical skills examination consisting of 16 varied stations (Clinical Assessment of Skills and Competencies, CASC).

No one doubts that to pass the exams necessitates a significant investment of time and energy, which detracts from trainees' experience on clinical placements, other educational opportunities, and their personal lives. Trainees' efforts should be rewarded with a process of learning and enrichment that develops their skills and knowledge, not simply another 'hoop to jump through' on their way through training. The MRCPsych courses offered by training hospitals go some way towards providing additional education, however, it is significant that trainees universally rely on practice questions rather than course attendance to pass exams. Some trainees will even pay for additional, privately run courses that focus solely on preparation for the exams. This suggests a fundamental disconnection between the exams and the learning objectives of training programmes that needs to be bridged.

The curriculum available to trainees is vague and fails to provide any real guidance towards training in the first 3 years. Content is frequently outdated and does not reflect the realities of clinical practice. The MCQ format is overly reliant on rote memorisation of lists of facts without regard to the context and complexities of clinical decision-making. The exam process neither encourages nor rewards trainees who take time to read broadly around the curriculum themes, instead relying on a narrow set of questions that are recycled year after year.

There is a lack of depth in the content tested, exemplified by the 'history' component which requires trainees simply to associate a list of important figures with a one-line description of their contribution. No attention is paid to the complex history of Western psychiatry or to important issues that are ongoing. Psychiatry more than any other field of medicine suffers from controversy regarding its role and relevance, and questions about aetiology, nosology, treatment and ethics. It is crucial for trainees to progress with an appreciation of these topics, yet the MRCPsych exams completely fail in this regard.

I suggest that a complete review of the MRCPsych curriculum and examination is overdue. The MCQ component should be reduced in favour of short-answer and/or clinical scenario formats. The curriculum should be updated to include more current research in basic sciences, as well as milestone papers in the history of psychiatric research. Historical, cultural and philosophical themes should be included in the curriculum and represented in assessments. Learning objectives for each theme should be specific, and accompanied by essential reading lists to guide trainees and exam questions.

In summary, if the goal of training is to produce highly skilled, well-rounded trainees, then the curriculum and examinations should reflect this. Instead, they assess a bare minimum level of competency, neglecting important developments and issues that are highly relevant to our daily practice. I believe that new psychiatrists deserve more than 'minimal' competence in return for their efforts, as does the profession, and most importantly, our patients.

Greg S. Shields, Specialist Registrar, Maudsley Hospital, London, email: gregory.shields@slam.nhs.uk

doi: $10.1192 / p b .39 .5 .262$

The Royal College of Psychiatrists' response: Examinations have been a feature of medical training for centuries both in undergraduate and postgraduate education. The primary purpose of such examinations has been to define a minimum standard that the public and fellow professionals have confidence in. In recent years there has been a drive for examinations to also inform the learning process and to be conducted in a format that is evidence based. The current MRCPsych examination was introduced in 2008 within parameters laid out by the Postgraduate Medical Education and Training Board (PMETB; Principles for Assessment Systems). The requirements of PMETB were for all Colleges to use assessment formats that were supported by evidence in the literature as being a reliable assessment method. As a consequence, all Colleges developed written paper examinations that were based on the multiple-choice question (MCQ) format and clinical examinations in an Objective Structured Clinical Examination (OSCE) format. These two formats are regarded as the most reliable. The written papers moved away from short-answer and essay questions as there are concerns about the reliability of these formats. The current MRCPsych written papers have extremely good reliability (Chronbach's $\alpha$ consistently greater than 0.9 ) and the Clinical Assessment of Skills and Competencies (CASC) also has good reliability (Chronbach's $\alpha$ 0.75-0.85). 